\title{
Endovascular treatment of iatrogenic arteriovenous fistula of the iliac vessel
}

\author{
Piotr Kaźmierski ${ }^{1, A-F}$, Mirosław Wąsiewicz, ${ }^{1, B, C}$, Jarosław Chrząstek ${ }^{2, B, C}$, Michał Pająk1,D-F \\ ${ }^{1}$ Department of Vascular, General and Oncologic Surgery, Copernicus Memorial Hospital, Łódź, Poland \\ 2 Department of Radiology, Copernicus Memorial Hospital, Łódź, Poland \\ A - research concept and design; $B$ - collection and/or assembly of data; $C$ - data analysis and interpretation; \\ $D$ - writing the article; $E$ - critical revision of the article; $F$ - final approval of the article
}

Address for correspondence
Piotr Kaźmierski

E-mail: ave151@wp.pl

\section{Funding sources}

None declared

Conflict of interest

None declared

Received on November 17, 2016

Reviewed on December 7, 2016

Accepted on March 28, 2017

\begin{abstract}
Background. latrogenic vascular injuries, due to the particular nature of such pathology, are associated with high morbidity and mortality in the postoperative period.

Objectives. The objective of this study was to present a case of non-classic approach to the therapy of iatrogenic arteriovenous fistula.

Material and methods. We present a case of a 17-year old female patient admitted to the Department of Vascular, General and Oncologic Surgery (Copernicus Memorial Hospital, Łódź, Poland) due to an iatrogenic injury to the common iliac vein and artery, following neurosurgical intervention on the spine. Two weeks prior to admission, the patient underwent surgery in the Neurosurgery Clinic for herniated nucleus pulposus and lumbar spine scoliosis. The imaging diagnostic revealed the presence of a pseudoaneurysm of the right common iliac artery and arteriovenous fistula between the right common iliac vessels. The patient was qualified for endovascular treatment. Two self-expanding covered stents were successfully deployed. The clinical and radiological outcome of the procedure was good. The postoperative period was uneventful. The patient was discharged home on the $3^{\text {rd }}$ postoperative day.
\end{abstract}

Results. The control examinations (directly after the procedure and 6, 12, 24, and 32 months thereafter) revealed full patency of the iliac vessels, as well as no recurrence of arteriovenous fistula, nor a pseudoaneurysm of the right common iliac artery. No symptoms of either chronic limb ischaemia or venous insufficiency were observed.

Conclusions. latrogenic vessel injury, being a complication of neurosurgical and orthopedic surgeries, may be overlooked and remain undetected both in intra- and postoperative period. Modern imaging techniques allow for an adequate diagnosis of the injury and planning the treatment of arteriovenous fistula. The endovascular procedures are the method of choice in patients with arteriovenous fistulas of iliac vessels, alternative to open surgery.

Key words: iatrogenic vessel injury, arteriovenous fistula, pseudoaneurysm of the common iliac artery, endovascular treatment

DOI

10.17219/acem/69859

\section{Copyright}

Copyright by Author(s)

This is an article distributed under the terms of the

Creative Commons Attribution Non-Commercial License

(http://creativecommons.org/licenses/by-nc-nd/4.0/) 


\section{Introduction}

Iatrogenic vascular injuries, due to the particular nature of such pathology, are associated with high morbidity and mortality in the postoperative period. ${ }^{1,2}$ This dangerous and sometimes life-threatening complication is being increasingly reported in the literature. It results mainly from the large number of diagnostic and therapeutic interventions requiring vascular access, as well as complex and extensive surgical repair procedures. The most dangerous early and late consequences of iatrogenic vessel injuries include intra- and postoperative hemorrhages from the large arteries and veins. ${ }^{3}$ The group of early complications consists of a pulsating hematoma, arterial and venous thrombosis, acute ischaemia of tissues and organs, whereas late complications include chronic ischaemia, post-thrombotic syndrome, pulmonary embolism, pseudoaneurysm formation and arteriovenous fistulas. ${ }^{1}$ Due to their local and systemic consequences, vascular fistulas pose a significant diagnostic and therapeutic issue. The size and localization of the fistula determine the clinical image, with typical vascular murmur, steal symptoms below the level of the fistula and venous overload leading to right ventricular failure. ${ }^{4-6}$ Early identification of the fistula and its successful treatment would allow us to avoid significant consequences for the patient's health. Constant development and the use of endovascular methods present a valuable opportunity for treating vascular injuries and mitigating their consequences, including arteriovenous fistulas. ${ }^{2,7-10}$ Vascular injury may complicate the course of other procedures and their serious consequences during specialist training of prospective surgeons. ${ }^{4}$ The early and proper diagnosis, as well as correct therapy, increases the patient's chances of surviving vascular injury and avoiding complications.

\section{Case report}

A 17-years old female patient (OHX) of Asian origin was referred to the Department of Vascular, General and Oncologic Surgery (Copernicus Memorial Hospital, Łódź, Poland) due to suspected arteriovenous fistula of the iliac vessels. Two weeks prior to admission, she was underwent surgery in the Neurosurgery Clinic for herniated nucleus pulposus and lumbar spine scoliosis. The discharge summary revealed that hemilaminectomy of L4, removal of L4/L5 discus, intravertebral stabilization using Capstone Medtronic and posterior L4/L5 stabilization using Legacy Medtronic were performed (Medtronic, Memphis, USA). The patient was discharged home on the $5^{\text {th }}$ postoperative day. The follow-up visits in the Neurosurgery Clinic (7 days after discharge) and Outpatient Clinic for Neurosurgery (in 6 weeks) were recommended, as well as permanent rehabilitation and physiotherapy. The patient reported unspecified pain in the right iliac area during her $1^{\text {st }}$ hospital stay, which was reported to the attending physician. During her follow-up visit in the Neurosurgery Clinic 7 days after being discharged, she reported the feeling of "ringing" within the abdominal cavity. The attending neurosurgeon ordered a next visit in the Outpatient Clinic for Neurosurgery in 2 weeks and referred her for ultrasound examination of the iliac and femoral vessels. The next day, the patient, accompanied by her mother, reported to the Outpatient Clinic for Vascular Surgery. The physical examination revealed good general condition in a circulatory and respiratory stable patient. Her heart rate was normal with $74 \mathrm{bpm}$, heart tones loud and clear, and blood pressure was 115/75 mm Hg. The abdominal palpation and auscultation revealed increased muscle tonus in the right iliac area over the pathological mass showing slight machinery murmur. The pulse over the arteries of the lower extremities was normal and symmetric. There was no edema of the lower extremities. The Doppler ultrasound revealed the hypoechogenic mass over right the iliac vessels with turbulent, high-amplitude flow (color and spectral Doppler). The accelerated, high-amplitude, machinery flow, typical for arteriovenous fistula was observed in the right iliac vein. The patient was urgently referred to the Department of Vascular, General and Oncologic Surgery (Copernicus Memorial Hospital, Łódź, Poland). The laboratory findings performed on admission revealed anemia (RBC: 2.51 T/L, Hb: 7.4 g/dL, Ht: 24.1\%, MCV: 96.0 fL, MCH: 29.5 pg, MCHC: $3.7 \mathrm{~g} / \mathrm{dL}$ ), leukocytosis (WBC: $13.51 \mathrm{G} / \mathrm{L}$ ) and thrombocytosis (PLT: $508 \mathrm{G} / \mathrm{L}$ ). The abdominal angio-MRI showed the presence of pseudoaneurysm of the right common iliac artery (Fig. 1). The patient was qualified for an iliac vessels angiography the next day, which confirmed the presence of large aneurysm of the right common iliac artery and arteriovenous fistula between right common iliac vessels (Fig. 2). The decision was made to treat the patient using endovascular method. The right femoral artery was punctured and self-expanding nitinol coated Fluency ${ }^{\circledR}$ $9 \times 40 \mathrm{~mm}$ stent was implanted (Bard Incorporated, Karlsruhe, Germany). Due to the observed leak to the aneurysm sack, the second Fluency ${ }^{\circledR}$ stent $(10 \times 40 \mathrm{~mm})$ was introduced. The control angiography revealed neither leak into

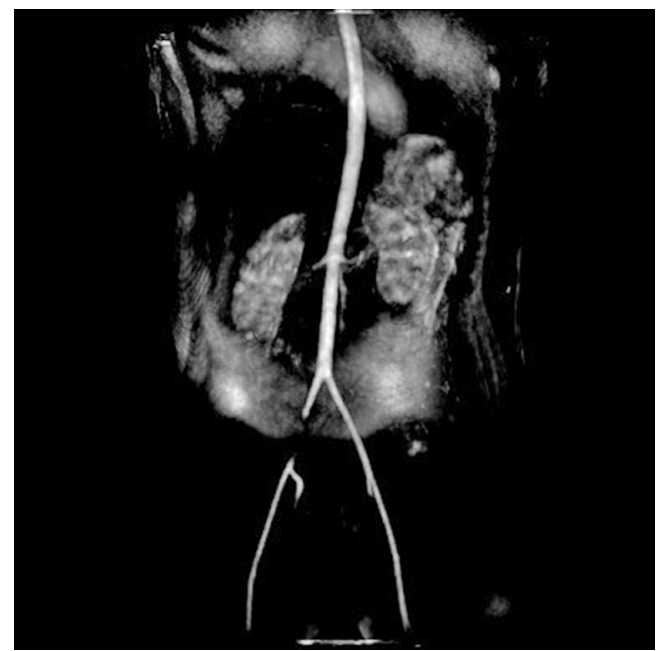

Fig. 1. Magnetic resonance imaging (MRI) angiography of the abdominal aorta and iliac arteries. The injury of right common iliac artery is clearly visible 


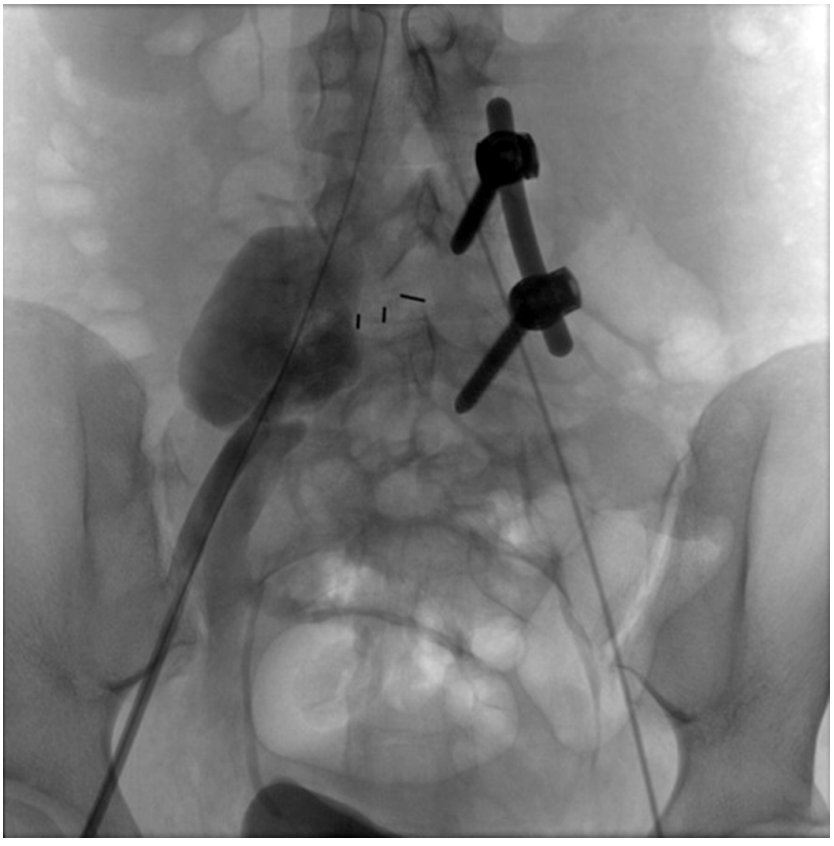

Fig. 2. Angiography of iliac vessels. A pseudoaneurysm and fistula between the right common iliac artery and common iliac vein is visible

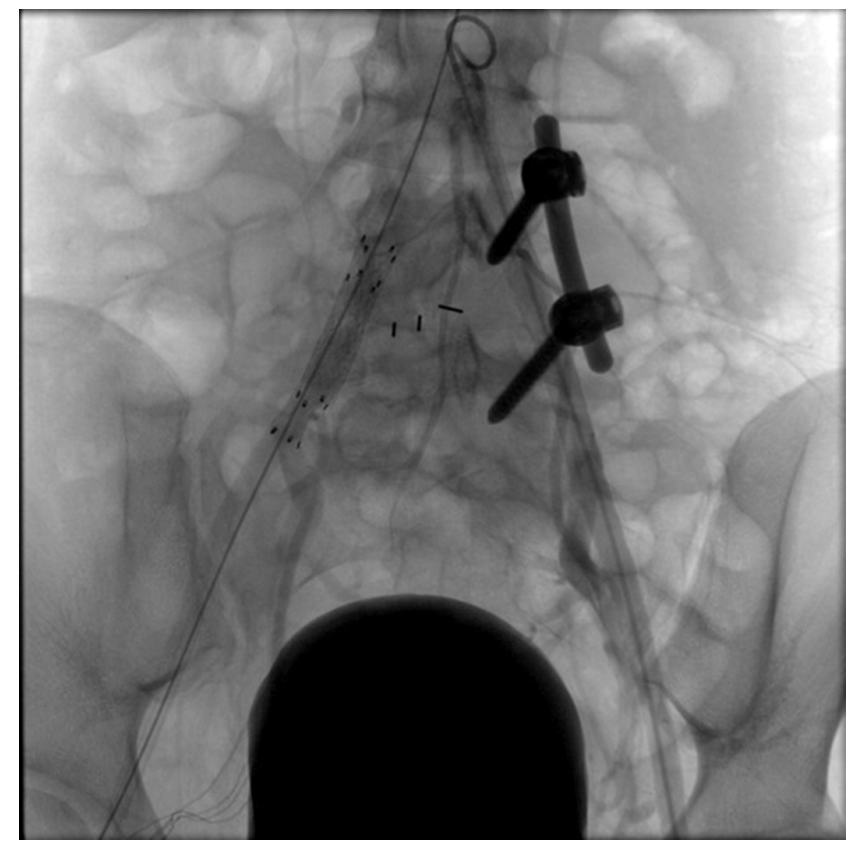

Fig. 3. Angiography of the iliac vessels after the implantation of 2 covered stents into the right common iliac artery

the aneurysm nor an arteriovenous fistula between the right common iliac artery and vein. A good flow through the right common, internal and external iliac arteries were observed (Fig. 3). Due to the identified anemia the patient received 2 units of group-matched red blood cell concentrate, which led to the normalization of morphotic parameters. In the postoperative period, the patient complained of slight pain in the right iliac region, which subsided after the administration of analgesics. The pulse over lower extremities arteries was normal and symmetric. The skin was normally colored and warm, with no edema. The postoperative period was uneventful. Once the compression dressing was removed the patient was mobilized and discharged in good general condition on the $3^{\text {rd }}$ postoperative day.

\section{Results}

Prior being discharged, the patient had the Doppler ultrasound of iliac vessels performed, which revealed the patency of implanted stents and normal flow through iliac veins and arteries. Neither a pseudoaneurysm nor an arteriovenous fistula were revealed. Both veins and arteries of the right lower extremity were patent and showed normal flow. The patient was followed up in the out-patient clinic for vascular surgery. The control examinations revealed neither ischaemia of the extremity nor impaired patency of the stents (after 6, 12, 24 and 32 months; Fig. 4-6). No recurrence of arteriovenous fistula was observed. The patient is well and remains active.

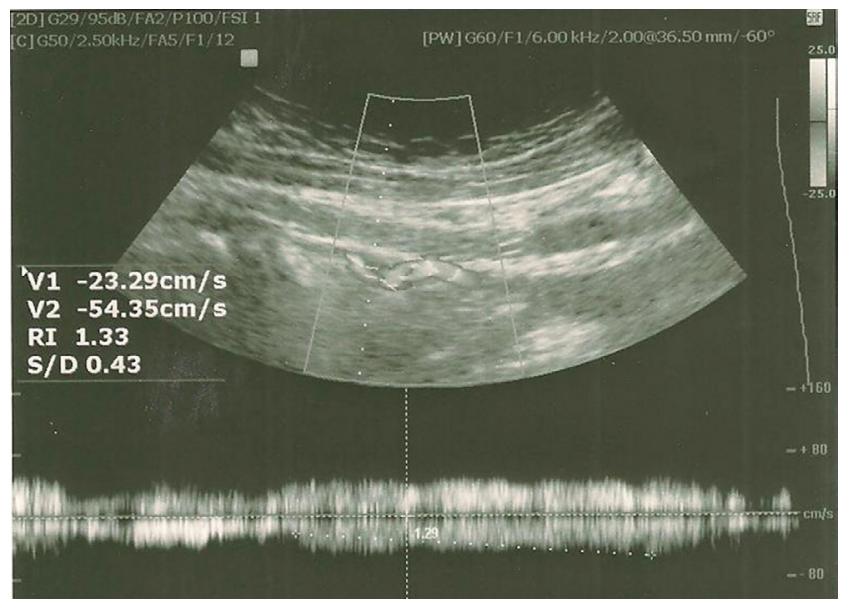

Fig. 4. Doppler ultrasound of the right iliac vein. Normal flow pattern in the right common iliac vein

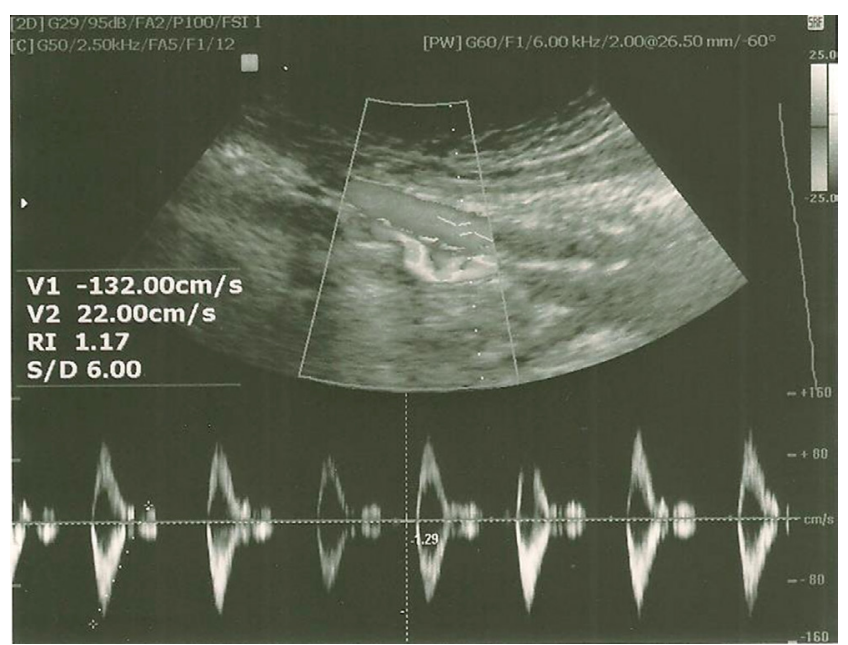

Fig. 5. Doppler ultrasound of the right iliac artery. Normal flow pattern in the right common iliac artery 


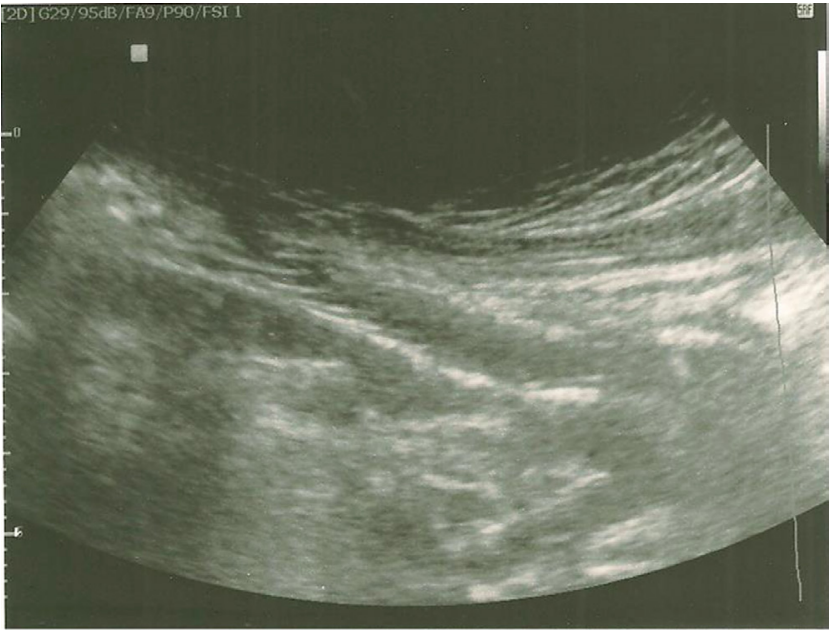

Fig. 6. Pelvis ultrasound. The arrow indicates stents implanted into the right common iliac artery

\section{Discussion}

Iatrogenic injury of the large pelvic vessels is one of the complications of neurosurgical and orthopedic surgeries. ${ }^{11,12}$ It is responsible for $0.05-0.3 \%$ of all complications occurring in such patients. ${ }^{12-14}$ The associated morbidity and mortality results from large vessels hemorrhage leading to hypovolemic shock. ${ }^{15}$ If undetected in the course of the primary operation, this may lead to the patient's death during or after the surgery. ${ }^{1,2,16,17}$ The possibility to overlook vessel injury in the perioperative period results from its frequent faint clinical manifestation and the lack of knowledge concerning the possible consequences of performed surgeries showed by the physicians. ${ }^{18}$ It is not uncommon that they become detected incidentally, many years after the injury. ${ }^{6,15,19,20}$ Due to the associated early and late complications, each such complication requires urgent diagnostic and adequate, specialist treatment. ${ }^{15,18,21}$ The diagnostic methods allow us to diagnose the patient with iatrogenic vessel injury include Doppler ultrasound, CT-angiography, MRI-angiography or angiography. ${ }^{11,21-23}$ The vessel injuries, including arteriovenous fistulas, are often detected intraoperatively, which is associated with high mortality rates. ${ }^{24}$ The therapy of vascular complications of neurosurgical and orthopedic procedures includes both open surgery and endovascular procedures. . $^{3,15,16,18}$ As immediate surgical treatment due to life-threatening condition, is a $1^{\text {st }}$ line treatment, the benefits of minimal invasive approach in the form of endovascular procedure may result in lower morbidity and mortality. $, 3,5,7-10,21,23,25,26 \mathrm{We}$, therefore, suggest establishing a complications' register. ${ }^{27}$

\section{Conclusions}

Iatrogenic vessel injury following neurosurgical and orthopedic procedures may be overlooked and remain undetected in the intraoperative and postoperative course.
Modern imaging techniques allow for the adequate diagnosis of the injury and planning of the treatment of arteriovenous fistula. The endovascular procedures are the method of choice in patients with arteriovenous fistula of iliac vessels, alternative to open surgery.

\section{References}

1. Hans SS, Shepard AD, Reddy P, Rama K, Romano W. latrogenic arterial injuries of spine and orthopedic operations. J Vasc Surg. 2011;53(2): 407-413.

2. Kufner S, Cassese S, Groha P, et al. Covered stent for endovascular repair of iatrogenic injuries of iliac and femoral arteries. Cardiovasc Revasc Med. 2015;16(3):156-162.

3. Kacem AH, Ben Amar M, Chelli H, Siala I, Frikha I. Rev Med Liege. 2006; 61(12):804-806.

4. Gallerani M, Maida G, Boari B, Galeotti R, Rocca T, Gasbarro V. High output heart failure due to iatrogenic arterio-venous fistula after lumbar disc surgery. Acta Neurochir (Wien). 2007;149(12):1243-1247.

5. Bürger T, Meyer F, Tautenhahn J, Halloul Z, Fahlke J. Percutaneous treatment of rare iatrogenic arteriovenous fistulas of the lower limbs. Int Surg. 1998;83(3):198-201.

6. Kim JH, Ko GY, Kwon TW, Nam GB, Cho YP. Endovascular treatment of an iatrogenic large vessel arteriovenous fistula presenting as high output heart failure: A case report. Vasc Endovasc Surg. 2012;46(6): 495-498.

7. Ohki T, Veith FJ. Five-year experience with endovascular grafts for the treatment of aneurysmal, occlusive and traumatic arterial lesions. Cardiovasc Surg. 1998;6(6):552-565.

8. Rocha L, Dalio MB, Joviliano EE, Piccinato CE. Endovascular approach for peripheral arterial injuries. Ann Vasc Surg. 2013;27(5):587-593.

9. Canaud L, Hireche K, Joyeux F, et al. Endovascular repair of aortoiliac artery injuries after lumbar-spine surgery. Eur J Vasc Endovasc Surg. 2011;42(2):167-171.

10. Kiguchi M, O'Rourke HJ, Dasyam A, Makaroun MS, Chaer RA. Endovascular repair of 2 iliac pseudoaneurysms and arteriovenous fistula following spine surgery. Vasc Endovasc Surg. 2010;44(2):126-130.

11. Hanel RA, Madalozzo LE, Araújo JC, Rodrigues MA, Truite LV. Common iliac artery aneurysm as complication of lumbar disc hernia surgery. Case report. Arq Neuropsiquiatr. 1999;57(3B):890-894.

12. Fruhwirth J, Koch G, Ivanic GM, Seibert FJ, Tesch NP. Vascular lesions in surgery of the hip joint. Unfallchirurg. 1997;100(2):119-123.

13. Szolar DH, Preidler KW, Steiner $\mathrm{H}$, et al. Vascular complications in lumbar disc surgery: Report of four cases. Neuroradiology. 1996;38(6): 521-525.

14. Abramovitz JN. Complications of surgery for discogenic disease of the spine. Neurosurg Clin N Am. 1993;4(1):167-176.

15. Bingol $\mathrm{H}$, Cingoz $F$, Yilmaz AT, Yasar $M$, Tatar $H$. Vascular complications related to lumbar disc surgery. J Neurosurg. 2004;100(3):249-253.

16. Zhou W, Bush RL, Terramani TT, Lin PH, Lumsden AB. Treatment options of iatrogenoc pelvic vein injuries: Conventional operative versus endovascular approach - case reports. Vasc Endovasc Surg. 2004;38(6):569-573.

17. Fruhwirth J, Koch G, Amann W, Hauser H, Flaschka G. Vascular complications of lumbardisc surgery. Acta Neurochir (Wien). 1996;138(8): 912-916.

18. Boonstra RH, van Tol CA, Coster E, Wisselink W. Two patients with initially unrecognised iatrogenic arteriovenous fistula and successful endovascular therapy following lumbar herniotomy and laparoscopic cholecystectomy. Ned Tijdschr Geneeskd. 2006;11:150(6):323-328.

19. Li Y, Fu Q, Liu A, et al. A case of iatrogenic ilio-iliac arteriovenous fistula initially misdiagnosed as deep venous thrombosis. Zhong Nan Da Xue Bao Yi Xue Ban. 2014;39(11):1217-1220.

20. Sin'kov MA, Murashkovskiĭ AL, Pogorelov EA, et al. Endovascular closure of iatrogenic arteriovenous anastomosis of the iliac artery and vein. Angiol Sosud Khir. 2014;20(1):80-84.

21. Wang EA, Lee MH, Wang MC, Lee HY. latrogenic left iliac-caval fistula: Imaging and endovascular treatment. AJR Am J Roentgenol. 2004; 183(4):1032-1034. 
22. Huwei L, Bei D, Huan Z, Zilai P, Aorong T, Kemin C. Arteriovenous fistula complicating iliac artery pseudoaneurysm: Diagnosis by $\mathrm{CT}$ angiography. JBR-BTR. 2002;85(2):104-105.

23. Cronin P, McPherson SJ, Meaney JF, Mavor A. Venous covered stent: Successful occlusion of a symptomatic internal iliac arteriovenous fistula. Cardiovasc Intervent Radiol. 2002;25(4):323-325.

24. Davidovic LB, Kostic DM, Cvetkovic SD, et al. Aorto-caval fistulas. Cardiovasc Surg. 2002;10(6):555-560.
25. Tsetis D. Endovascular treatment of complications of femoral arterial access. Cardiovasc Intervent Radiol. 2010;33(3):457-468.

26. Onal B, Ilgit ET, Kosar, Akkan K, Gümüş T, Akpek S. Endovascular treatment of peripheral vascular lesions with stent-grafts. Diagn Interv Radiol. 2005;11(3):170-174.

27. McPherson R, Buckenham T. Complications and great escapes: Equipment and techniques. Semin Intervent Radiol. 2014;31(4):361-369. 